\title{
Knowledge management assessment in Petrochemical industries
}

\author{
Ammar Feyzi ${ }^{a^{*}}$, Hosein Rezai ${ }^{b}$ and Mohammadreza Ghorbanian ${ }^{c}$ \\ ${ }^{a}$ Young Researchers and Elite Club, Saveh Branch, Islamic Azad University, Saveh, Iran \\ ${ }^{b}$ M.A. Student, Industrial Engineering, Islamic Azad University of Parand, Tehran, Iran \\ ${ }^{c}$ Faculty Member, Accounting Department, Islamic Azad University of Shahr-e Qods, Tehran, Iran \\ C H R O N I C L E \\ Article history: \\ Received February 25, 2016 \\ Received in revised format: \\ March 28, 2016 \\ Accepted August 22, 2016 \\ Available online \\ August 232016 \\ Keywords: \\ Performance assessment \\ Knowledge management \\ Petrochemical industries \\ Balanced scorecard \\ DEMATEL \\ ORESTE Technique

\begin{abstract}
A B S T R A C T
Knowledge management strategies are considered as the foundation of learning organizations. One of the problems of Iranian organizations is the assessment of knowledge management processes. The purpose of the present study is to present an applied organized model for the assessment of knowledge management performance in six dimensions, i.e., the financial dimension, stakeholders, local processes, growth and learning, employee satisfaction, and environment and community; identifying and investigating the correlation among the criteria; mapping network relations; weighing the indices using DEMATEL Technique; ranking assessment dimensions of knowledge management using ORESTE Technique; drawing strategic map; and designing Balanced Scorecard for improved performance of knowledge management. The population and sample of the study included 25 petrochemical Tehran managers and senior experts in information technology section. The results of this study provides a comprehensive view for the decision makers of Iran Petrochemical Industries for an improved performance in knowledge management.
\end{abstract}

\section{Introduction}

During the past few decades, drastic changes in the realm of business have shifted the focus of many organizations from tangible to intangible assets, one of the most prominent of which is knowledge. The intense global competition, rapid technological changes, and increased customer demands have forced many organizations to look for sustainable competitive advantages. Under such circumstances, most firms try to distinguish themselves from other companies through knowledge (Ngai \& Chan, 2005). To compete in business, firms have to make sure that knowledge is created, conveyed and shared inside their organizations, properly and the organization's environment plays an essential role for the advancement of this goal (Samimi \& Aqayi, 2012). Many organizations such as Xerox and General

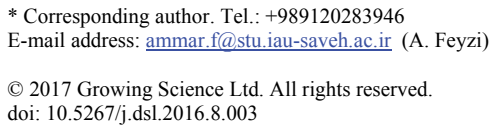


Electric have committed for the creation of learning organizations, in which people continuously expand their capacities for creation of desirable outcomes. In such organizations people constantly try to learn (Luo et al., 2015). Therefore, to have successful organizations in the current era, knowledge should be exchangeable as a capital between humans and should have the potential for growth. Problem solving knowledge can be acquired and then knowledge management will be able to develop organizational learning, which leads to creation of another knowledge (Oinas-Kukkonen, 2006).

According to the above points and by considering the environmental uncertainty, which is currently challenging organizations, companies have to switch to the learning mode to improve their business and maintain their competitive advantage. Organizational learning provides suitable bases for development of structured knowledge in organizations. To develop learning abilities an organization should complete its knowledge management processes satisfactorily. An organization will not be able to develop group or individual learning abilities without the aid of knowledge management. Using new and dynamic methods, organizations and organizational members should learn to use dynamic and up to date methods instead of old and static methods to improve their knowledge (Ribeiro, 2015).

The main question of this research is to determine the appropriate criteria in knowledge management evaluation in petrochemical industries. Moreover, we need to determine the extent these criteria are affected and affect in DEMATEL (Decision Making Trial and Evaluation Laboratory. We also need to know which of the six dimensions including finance, stakeholders, local processes, growth and learning, employee satisfaction, and society and environment is more important using ORESTE (Organisation, Rangement Et Synthese de donnee's Relationnelles) technique. Finally, How should the strategic map and Balanced Scorecard (BSC) be designed and illustrated for the petrochemical industry?

The objectives of the present research are to propose an applied formulated model for evaluation of knowledge management from six aspects (namely finances, stakeholders, local processes, growth and learning, employee satisfaction, and environment and society); to identify and study the mutual relationship between criteria; map network relations; assign weights to the criteria using DEMATEL; to rank knowledge management evaluation dimensions using ORESTE; to prepare a strategic map; and to design a balanced scorecard to improve knowledge management in Iran's petrochemical industries. To the best of our knowledge, no study has been so far conducted to identify key factors in the success of knowledge management evaluation and combination of these factors with multi-criteria decisionmaking models (such as DEMATEL, ORESTE, and the BSC strategy-based approach with six dimensions), especially in the Iranian petrochemical industries. The spatial scope of this study includes Iran's petrochemical industries, and its thematic scope includes identification and ranking of key factors in the success of knowledge management evaluation with a new strategy-based hybrid approach. As compared to other solely statistical studies, the innovation of this research is the use of mathematical models to assign weights and rank key factors, illustrate a strategic map, and design a scorecard.

\section{Research Theoretical Fundamentals}

\subsection{Meaning of Knowledge Management}

Knowledge management is the process of regular selection, organization, refinement, and presentation of information that leads to improvement of organization's members and reinforcement of organizational memory. This process shall help the organization learn from its experiences constantly and corrects itself. Wiig (1997) defines knowledge management as an organizational activity, which is aimed at creation of a social and technical environment, which can be used to create knowledge and share it with others. Prosak defines knowledge management as an attempt to disclose assets that are hidden in the minds of organizational members and to turn the hidden asset to an organizational asset that can be accessed by all of the organization's employees. Petrisch believes that knowledge 
management is the process of acquisition of accurate knowledge by appropriate people at the right time and place so that they can make the best of knowledge to attain organizational goals (Lin et al., 2015).

\subsection{Knowledge Management Evaluation Models}

Knowledge management evaluation is great importance because it could be used to determine the organizational learning path for creation of unique competitive advantages. In other words, every organization needs instruments to continuously assess and evaluate the effectiveness and efficiency of knowledge management to improve its performance. Different models have been examined and implemented by various researchers to evaluate knowledge management, some of the most important of which are discussed in this section (Khamseh \& Qazayi., 2014).

\subsection{Balanced Scorecard Evolutions}

Kaplan (1983) is believed to be the first who criticized traditional management control in general and performance assessment in particular and finally introduced the balanced scorecard framework in an article titled "Balanced Scorecard: sizes that guide performance". The technique influenced organizations such that in 1996 it was stated that BSC was the greatest business development in the last 75 years. Since its development in the early 1990s, BSC has changed from different aspects. Fig. 1 shows the evolution of balanced scorecard (Jafari et al., 2009).

\begin{tabular}{|c|c|c|}
\hline First Generation & Second Generation & ThirdGeneration \\
\hline for performance evaluation(1990) & BSC as a management & $\begin{array}{l}\text { BSC as a framework for change } \\
\text { since } 2001 \text { to present }\end{array}$ \\
\hline *Performance Sizes & $\begin{array}{l}\text { *Organization's learning at } \\
\text { the end of the course }\end{array}$ & * Performance Sizes \\
\hline *Solution segregation & *Identifying and solving & * Solution segregation \\
\hline *Key goals and key & operational problems & * Key goals and key \\
\hline performance indicators & $\begin{array}{l}\text { *Feedback on future period } \\
\text { plan }\end{array}$ & performance indicators \\
\hline $\begin{array}{l}\text { *Performance-related } \\
\text { reward }\end{array}$ & *Development of & $\begin{array}{c}\text { * Performance- related } \\
\text { reward }\end{array}$ \\
\hline
\end{tabular}

Fig. 1. Evolution of Balanced Scorecard

\subsection{Research Background}

Lin et al. (2015) performed an analysis on the role of knowledge social centers in sharing committee members of social knowledge networks by collecting some information from Yahoo social networks. The objective of this research was to help understand and identify the key factors in sharing social knowledge networks and to present a framework for effective sharing of a mechanism for adding to usefulness of social networks. Serenko and Dumay (2015) carried out a study on the key success factors in the employment of the knowledge management system for the pharmaceutical industry. They identified seven factors as the factors involved in the success of knowledge management systems: 1) imitation strategy and effective knowledge structure; 2) organizational culture; 3 ) information system infrastructure; 4) involvement and training of people; 5) leadership and strong commitment of senior 
management; 6) learning environment and resource control; 7) evaluation of professional training and team work. Sigala and Chalkiti (2015) identified different key factors involved for the successful implementation of knowledge management in an organization's task scopes. Some of these key factors included strategy, human resource management, information technology, marketing, and quality. Moreover, numerous studies have been conducted to evaluate knowledge management in various organizations. Patil and Kant (2014) identified the key success factors in evaluation of knowledge management in Supply chain. Through the means of interviews and using a hybrid mathematical method the researchers identified the key success factors in knowledge management evaluation with an emphasis on commercial strategies. Results of this research indicated that public air services and facilities, which are based on software and hardware (or IT in general) could improve the quality of services and performance of these airlines and can accelerate the discussions of documentation and sharing of knowledge. Samimi and Aqayi (2012) evaluated knowledge management in the financial and non-financial sectors. Afterwards, based on the latest studies on the research topic a model was proposed for evaluation of knowledge management systems, performance criteria and the relationship between the criteria. The researchers proposed the following dimensions: knowledge management system quality, knowledge or information quality, user satisfaction, perceived advantages and benefits of knowledge management system, and utilization of knowledge management system.

Yazdani et al. (2011) identified the key success factors in knowledge management evaluation in Iranian petrochemical industries. The objective of their research was to facilitate development of knowledge management from different aspects such as culture, structure, and technology in a factory in Zahedan associated with the Iranian petrochemical industries. Results of their research indicated that culture is of significant importance for development and implementation of knowledge management in the petrochemical industries. Feyzi et al. (2014) identified and prioritized the key success factors in implementation of knowledge management, assign weights to these factors using the fuzzy analytical hierarchy process, and prioritize the factors using fuzzy TOPSIS technique. They introduced the following factors as the key factors involved in implementation of knowledge management: technology infrastructure, organizational infrastructure, employees' motivation, senior management support and commitment, involving employees in knowledge process, organizational culture, empowering employees, evaluation and ease of access to knowledge, and knowledge management assessment. Heydari et al. (2013) studied the effect of vital factors on knowledge management implementation in Ministry of Agricultural Jihad based on the following ten essential factors: organizational culture, senior management commitment, cooperation, teaching, teamwork, empowering, information systems, performance assessment, modeling, and knowledge structure. Rabiyi et al. (2009) implementated knowledge management as a valuable experience in Tehran Oil Refinery. Different stages of knowledge management were explained through a case study of Tehran Oil Refinery. This study was arranged with regard to culture, information technology, and knowledge processes, and then statistical tests were used to analyze the data resulted from the questionnaires. Results of this study revealed that the conditions of culture, knowledge processes, and information technology were not satisfactory in Tehran Oil Refinery and call for further attention. Vaezi and Moslemi (2009) identified organizational factors influencing satisfactory implementation of knowledge management system in System Group Co. The organizational culture and organizational structures were studied as two of the various organizational factors. Moreover, knowledge generation and knowledge transfer were among the other several components considered in this research. Results of this research revealed that there was a positive significant relationship between organizational factors (organizational culture and organizational structure) and generation and transfer of knowledge (as the components).

\section{Research Methodology}

Survey studies are the most general form of studies in social sciences, which are based on opinions of people who are directly involved with the research problem (Feyzi \& Soloukdar, 2014). Since the objective of the present research was to identify knowledge management evaluation criteria, the descriptive survey research method was used for the first part of this research. One of the most 
important advantages of this research method is the ability to extend and generalize its results. In view of the objective, motivation and advantage of this research, it is considered an applied study, because its results could be used to arrange the organization's future plans (i.e. Iran's petrochemical industries). This research was conducted using the meta-analysis qualitative methods and cause and effect maps (DEMATEL). Hence, to design special networks of components and factors influencing evaluation of knowledge management in Tehran petrochemical companies, first the factors were identified based on the results of previous research, and then the network maps were prepared using the DEMATEL technique. The statistical population for the present research included 25 senior managers and experts from IT divisions of Tehran petrochemical companies. Due to the limitedness of the population size, the complete enumeration method was used to determine the sample size. To examine the validity of the questionnaires a face validity assessment was carried out and reliability of questionnaires was approved with a Cronbach's alpha coefficient of 0.874. In this study, questionnaire no. 1 was first designed to study the model and screen the variables. Afterwards, questionnaire no. 2 was designed for pair-wise comparisons and analysis of the mutual effects of research variables so as to carry out a DEMATEL analysis. Questionnaire no. 3 was distributed among the experts to determine the significance and ranking of BSC dimensions in evaluation of knowledge management using the ORESTE technique. To analyze the data quantitative and mathematical techniques namely DEMATEL and ORESTE were used to study the intensity of interrelationships between variables and rank different dimensions of knowledge management. The qualitative analysis was also conducted using the balanced scorecard method.

\subsection{Research Executive and Conceptual Model}

Comprehensive examination of a management phenomenon calls for a suitable conceptual model. A conceptual framework or model reflects the theoretical relations between important variables (Sohrabi et al., 2010). The conceptual model for the present study expresses the relationships between variables. First, mathematical models are introduced and an evaluation and examination of DEMATEL decisionmaking and ORESTE techniques were carried out. Afterwards, by presenting an executive and conceptual model different steps from problem identification to conclusion (executive model) were studied. Finally, the research variables and criteria (conceptual model) were introduced.

\subsubsection{Decision-Making Trial and Evaluation Technique (DEMATEL)}

The Decision-Making Trial and Evaluation Technique (DEMATEL) was developed by Fontela and Gabus (1976). DEMATEL, as a decision-making method based on pair-wise comparisons, uses expert opinions to extract the factors of a system and organizes the factors systematically using the principles of the graphs theory to present a hierarchical structure of the system's factors along with their mutual interactions and effects. In this process, it determines the intensity of the aforementioned effects in the form of numerical scores. DEMATEL is adopted to identify and examine the mutual relations between criteria and to map network relationships. Since directed graphs provide a better representation of the relationships between the system elements, DEMATEL is based on diagrams, which can divide the involved factors into the groups of causes and effects. It can also turn the relationship between the factors into a comprehensible structural model. DEMATEL was originally developed to study highly complicated global problems. It could also be used to structuralize a sequence of given information. It examines the intensity of relationships through a scoring process, searches for feedbacks with significance, and accepts inalienable relations. Different steps of DEMATEL are as follows: designing a questionnaire and collecting information on relative dependence of criteria based on expert opinions; calculating the direct relationship matrix $(\hat{M})$; calculating the normal direct relationship matrix (M); calculating the total relations matrix (direct and indirect dependency) $(\mathrm{T})$; calculating the normal matrix of total relations with an acceptance threshold; mapping network relations based on the $\mathrm{R}$ and $\mathrm{J}$ vectors (Serenko \& Dumay, 2015). 


\subsubsection{ORESTE Technique}

If the objective of a multi-criteria decision-making problem is to rank $\mathrm{m}$ options based on $K$ criteria, and if a poor sequence is defined for each criterion on a set of options, and if the relative importance (weight) of each criterion is expressed through another poor sequence, then the basics of one of the ways of superiority of MADM to ORESTE are provided. This method provides an instrument which is capable of completely ranking decision options and showing the contradictions between options. The ORESTE technique was introduced by Marc Roubens, the professor of Polytechnic University of Belgium (1979) in a conference on multi-criteria decision-making problems. He introduced his first idea of a new multi-criteria decision-making method called ORESTE (or the collective ranking method for comparing sequential evaluations of options based on criteria). Roubens was trying to use ORESTE to avoid the practical obligation associated with ELECTRE in determining the weights of criteria. After his first presentation in this conference, Professor Roubens presented ORESTE in two other articles (Ali Nezahd et al., 2011). Fig. 2 shows the research executive model, while Fig. 3 depicts the conceptual model of this research.

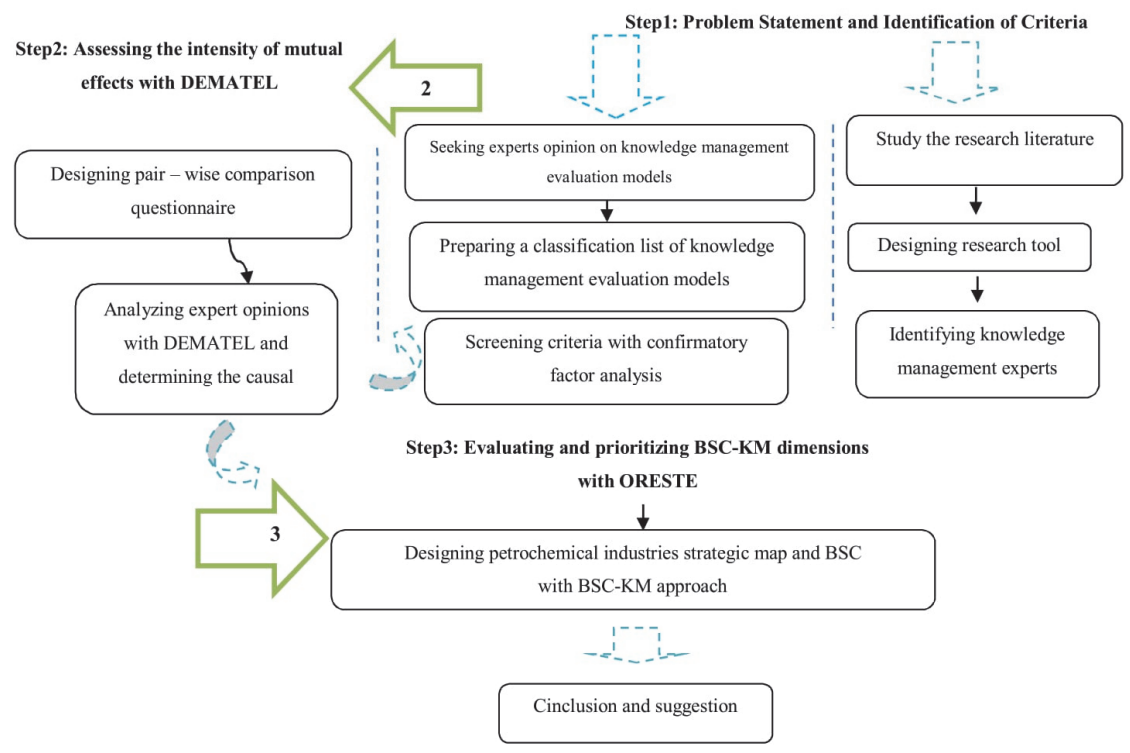

Fig. 2. Research executive model

\subsubsection{Preparing the Knowledge Management Strategic Map for Petrochemical Industries}

Before preparing the strategic map it is necessary to understand the goals, missions, and perspectives of this organization (National Petrochemical Company). The strategic map is plays a determining role in decisions made by senior managers and exports to achieve competitive advantage and conquer the market. Therefore, the criteria for each dimension, the organization-specific balanced scorecards, and the environment shall be determined and selected. First the goals, mission, and perspective of Tehran Petrochemical Company are defined. Afterwards, strategic maps are prepared based on criteria, aspects, goals, missions and perspectives.

\subsubsection{National Petrochemical Company's Mission Statement}

As a developmental organization, National Petrochemical Company relies on more than half a century of effective experience and uses its intellectual and human capitals for the purpose of major planning, policy making, adjustment, infrastructure development, facilitation, and support for sustainable development of petrochemical industries with an aim to reduce crude retail and complete the value chain. National Petrochemical Company is playing a key role by relying on social responsibility to protection of the environment and national resources, appreciating value creation, accountability, and 
respective the rights of stakeholders involved in the country's economic advancement and improvement of the nation's quality.

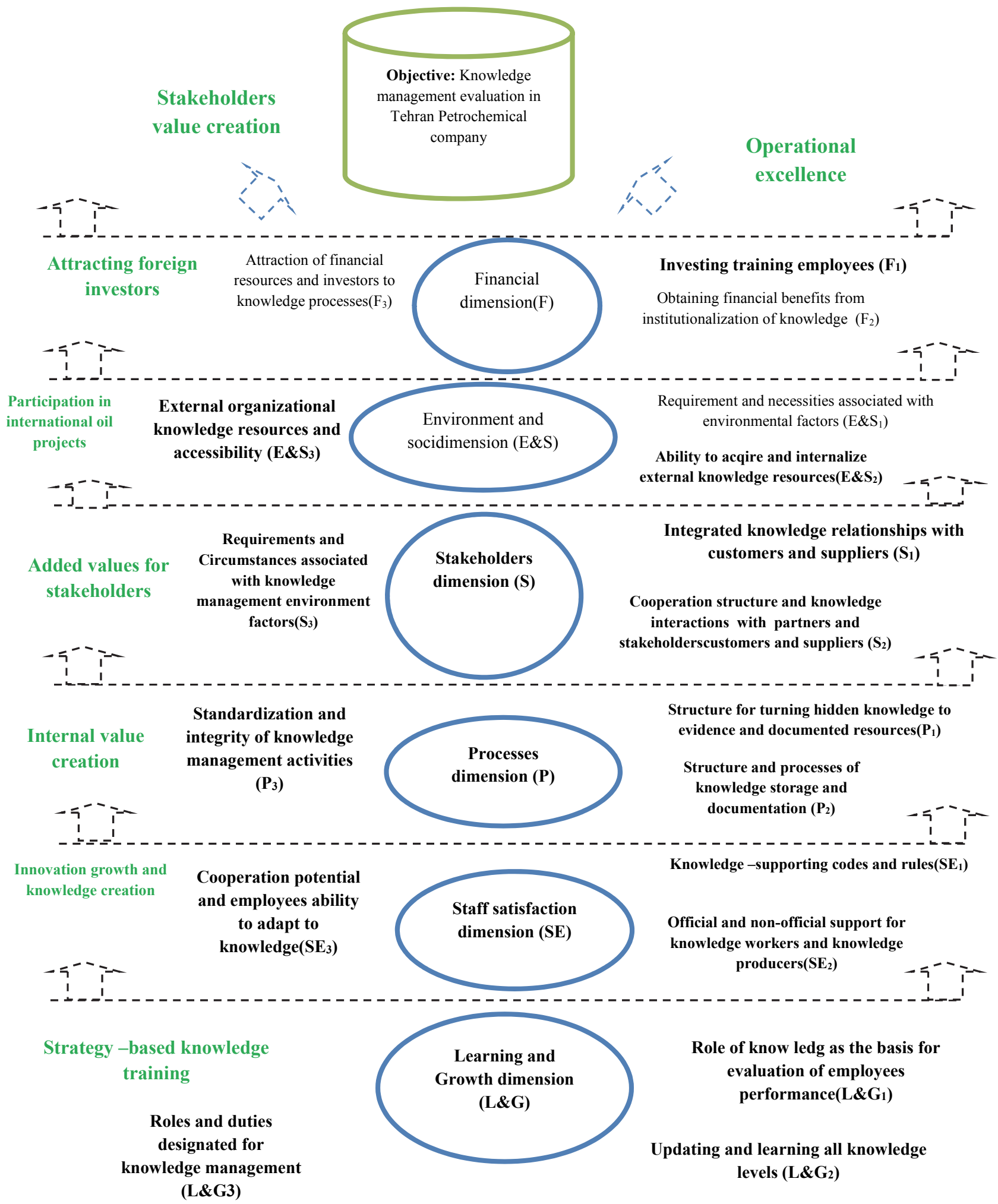

Fig. 3. Present Conceptual model and strategic map of petrochemical industries with KM-BSC 


\section{Research Findings \& Results}

\subsection{Analysis of Intensity of Relationships between Knowledge Management Dimensions with}

\section{DEMATEL}

After identifying the criteria and dimensions and designing the research conceptual model, questionnaire no. 1 was distributed among 25 petrochemical experts to examine the intensity of mutual relationships between knowledge management evaluation dimensions. The questionnaire covered six dimensions with scores ranging from 0 to 4 . This phase determine the hierarchy or possible structure of elements. The order of influence of the given elements of a problem on other elements or the order in which the elements are influenced determines the possible structure of the hierarchy of those elements in improvement or solving of the problem. Fig. 4 shows a view of rules governing the vertices and the intensity of mutual effects calculated for the elements.

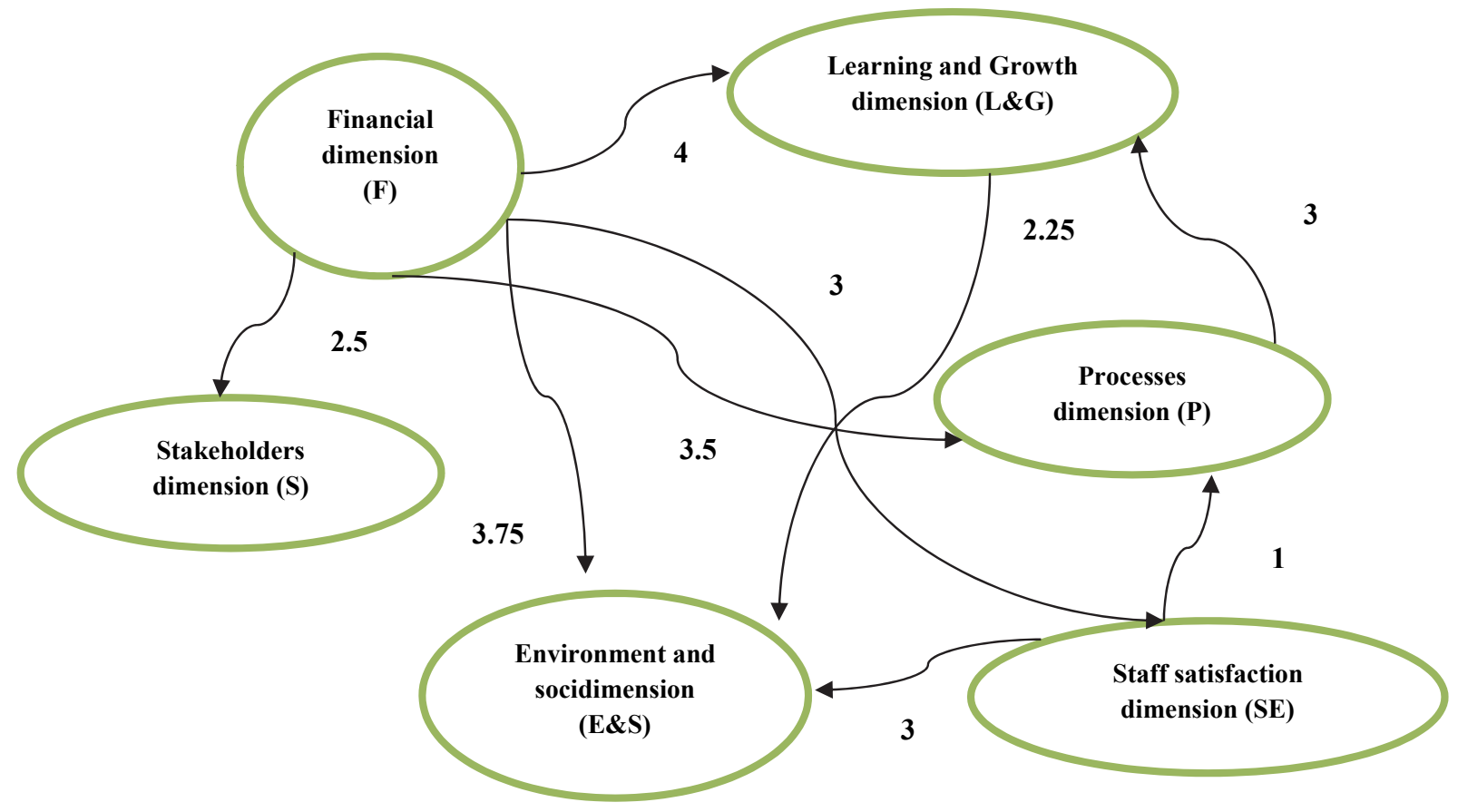

Fig. 4. Diagraph of KM evaluation dimensions resulted from DEMATEL

The sum of the vertices of this diagraph is shown as follows:

$N=\{F, S, P, L \& G, S E, E \& S\}$

\subsubsection{Showing final scores as a matrix}

The final scores for the existing relations in the diagraph are shown as a matrix called $\hat{M}$. The relations in the diagraph are shown as a matrix of intensity of system Eq. (1).

$$
\begin{array}{c|cccccc} 
& F & S & P & L \& G & S E & E \& S \\
F & 0 & 2.5 & 3.5 & 4 & 3 & 3.75 \\
S & 0.4 & 0 & 0 & 0 & 0 & 0 \\
P & 0.286 & 0 & 0 & 3 & 0 & 0 \\
L \& G & 0.25 & 0 & 0.333 & 0 & 0 & 2.25 \\
S E & 0.333 & 0 & 0 & 0 & 0 & 3 \\
E \& S & 0.267 & 0 & 0 & 0.444 & 0.333 & 0
\end{array}
$$


The entry at each intersection (e.g. 4 in the first row and fourth column) shows the intensity of influence of an element from that row on another element from that column ( $F$ on $L \& G$ ). Moreover, at each intersection zero shows the lack of relationship between corresponding elements of that intersection. After completing the scores matrix in relation to each dimension, the sum of each row is calculated, and then the maximum value is inversed and is selected as the $\alpha$ coefficient. Eq. (2) shows this operation.

$$
\begin{array}{c|ccccccc|} 
& F & S & P & L \& G & S E & E \& S & \sum R \\
F & 0 & 0.25 & 3.5 & 4 & 3 & 3.75 & \mathbf{1 4 . 5} \\
S & 0.4 & 0 & 0 & 0 & 0 & 0 & 0.4 \\
P & 0.286 & 0 & 0 & 3 & 0 & 0 & 3.286 \\
L \& G & 0.25 & 0 & 0.333 & 0 & 0 & 2.25 & 2.833 \\
S E & 0.333 & 0 & 0 & 0 & 0 & 3 & 3.333 \\
E \& S & 0.267 & 0 & 0 & 0.444 & 0.333 & 0 & 1.044
\end{array}
$$

According to Eq. (2) the maximum value belongs to row F, or the financial dimension (14.5). After inversing this value, the resulting alpha is $\alpha=\frac{1}{14.5}=0.069$. Now each element in matrix (1) $\hat{M}$ is multiplied by the $\alpha$ value, and results are shown in Eq. (3), M.

$$
\begin{array}{c|cccccc} 
& F & S & P & L \& G & S E & E \& S \\
F & 0 & 0.1725 & 0.2415 & 0.276 & 0.207 & 0.2587 \\
S & 0.0276 & 0 & 0 & 0 & 0 & 0 \\
P & 0.0197 & 0 & 0 & 3 & 0 & 0 \\
L \& G & 0.0172 & 0 & 0.023 & 0 & 0 & 0.1552 \\
S E & 0.023 & 0 & 0 & 0 & 0 & 0.207 \\
E \& S & 0.0184 & 0 & 0 & 0.0306 & 0.023 & 0
\end{array}
$$

Table 2

Sequence of influence of dimensions affecting knowledge management evaluation in Tehran

\begin{tabular}{|c|c|c|c|c|c|c|c|}
\hline $\begin{array}{l}\text { Based on } \\
\text { R-J }\end{array}$ & $\begin{array}{l}\text { Sequence } \\
\text { of } \\
\text { elements }\end{array}$ & $\begin{array}{c}\text { Based on } \\
\quad \mathrm{R}+\mathrm{J}\end{array}$ & $\begin{array}{l}\text { Sequence } \\
\text { of } \\
\text { elements }\end{array}$ & $\begin{array}{c}\text { Based on } \\
\text { maximum } \\
\text { column sum } \\
(\mathrm{J})\end{array}$ & $\begin{array}{l}\text { Sequence } \\
\text { of } \\
\text { elements }\end{array}$ & $\begin{array}{l}\text { Based on } \\
\text { maximum row } \\
\text { sum }(\mathrm{R})\end{array}$ & $\begin{array}{l}\text { Sequence } \\
\text { of } \\
\text { elements }\end{array}$ \\
\hline 0.793 & $\mathrm{~F}$ & 6.381 & $\mathrm{~L} \& \mathrm{G}$ & 3.901 & $\mathrm{~L} \& \mathrm{G}$ & 3.189 & $\mathrm{~F}$ \\
\hline 0.396 & $\mathrm{P}$ & 5.585 & $\mathrm{~F}$ & 2.396 & $\mathrm{~F}$ & 2.48 & $L \& G$ \\
\hline 0.128 & $\mathrm{E} \& S$ & 3.954 & SE & 1.954 & SE & 2 & $\mathrm{SE}$ \\
\hline 0.058 & $\mathrm{~S}$ & 2.532 & $\mathrm{~S}$ & 1.237 & $\mathrm{~S}$ & 1.396 & $\mathrm{P}$ \\
\hline 0.046 & SE & 2.396 & $\mathrm{P}$ & 1 & $\mathrm{P}$ & 1.295 & $\mathrm{~S}$ \\
\hline-1.421 & L\&G & 1.872 & $\mathrm{E} \& \mathrm{~S}$ & 0.872 & E\&S & 1 & E\&S \\
\hline
\end{tabular}
Petrochemical Industries

This phase determines the hierarchy or possible structure of elements. The sequence of influence of the given elements of a problem on other elements or the influence on the given elements determine the possible structure of hierarchy of those elements in improvement or solving of the problem. Table 2 shows the sequence of influence of elements on one another. According to the results of Table 2, the F element (i.e. financial dimension) is the most effective dimension, and of the six dimensions, this dimension has the highest numerical value based on its row sum (R). Therefore, it is the most effective dimension among the dimensions of knowledge management evaluation in Tehran Petrochemical Industries. Moreover, based on the maximum column sum, the L\&G element (or learning and growth) is the most influenced dimension. Fig. 5 presents the cause and effect diagram for dimensions of knowledge management evaluation. Due to the limited size of this article the cause and effect results associated with 18 criteria were omitted and they were used to assign weights to ORESTE criteria. 


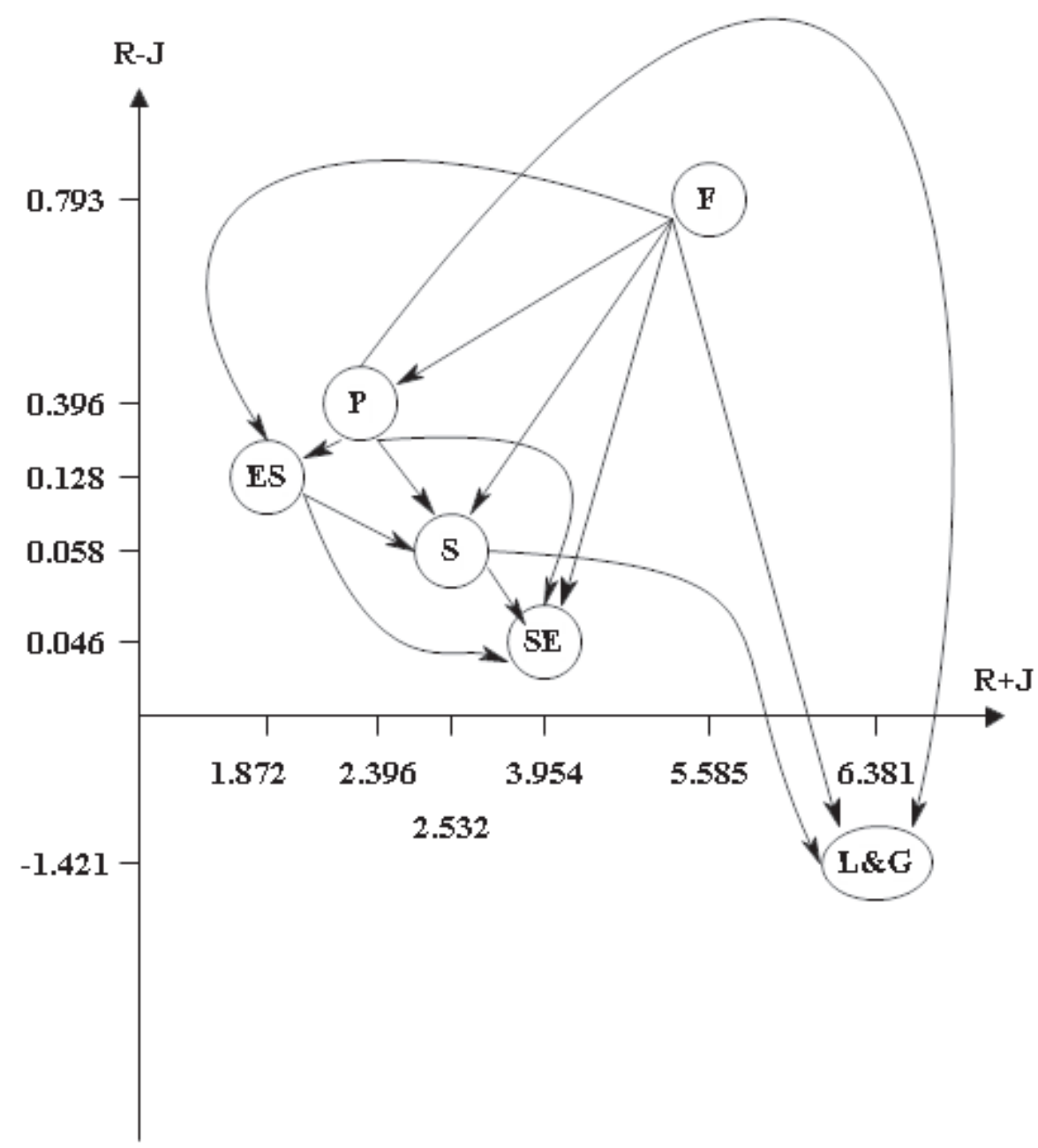

Fig. 5. Causal diagram of dimensions of knowledge management evaluation in Tehran Petrochemical Industries with DEMATEL

According to Fig. 5, the financial dimension has the highest effect whereas the growth and learning dimension accepts the highest effect as compared to other dimensions of knowledge management evaluation with BSC.

\subsection{Evaluation of Knowledge Management in Tehran Petrochemical Company with ORESTE}

After determining the intensity of the effects of dimensions with DEMATEL, the performance of knowledge management in Tehran Petrochemical Industries was examined with ORESTE in the following six dimensions: financial, stakeholders, internal processes, growth and learning, staff satisfaction, and environment and society. The criteria weights obtained from DEMATEL were ranked based on questionnaire no. 2 and expert opinions. Table 3 shows the weights resulted from DEMATEL.

According to Table 3, results of prioritization of knowledge management evaluation criteria indicate that investment in employee training has the first place and is following by other criteria, which have the second to eighteenth places. According to Table 4, in Tehran Petrochemical Industries, internal processes have the first rank in implementation of knowledge management regarding BSC. The second to sixth places also belong to financial dimension, learning and growth, stakeholders, staff satisfaction, and environment and society in the mentioned order. 
Table 3

Priority of knowledge management evaluation criteria with DEMATEL

\begin{tabular}{clccc}
\hline No. & Criteria & Weight & Priority & Corresponding criterion \\
\hline $\mathbf{1}$ & Investment in training of employees & $\mathbf{0 . 2 4 6}$ & $\mathrm{r}_{1}=1$ & $\mathrm{~F}_{1}$ \\
$\mathbf{2}$ & Obtaining financial benefits from institutionalization of knowledge & $\mathbf{0 . 2 2 3}$ & $\mathrm{r}_{2}=2$ & $\mathrm{~F}_{2}$ \\
$\mathbf{3}$ & Attraction of financial resources and investors to knowledge processes & $\mathbf{0 . 1 7 5}$ & $\mathrm{r}_{3}=3$ & $\mathrm{~F}_{3}$ \\
$\mathbf{4}$ & Requirements and necessities associated with environmental factors & $\mathbf{0 . 0 9 6}$ & $\mathrm{r}_{4}=4$ & ${\mathrm{E} \& \mathrm{~S}_{1}}$ \\
$\mathbf{5}$ & External knowledge resources and their accessibility & $\mathbf{0 . 0 6 4}$ & $\mathrm{r}_{5}=5$ & $\mathrm{E \& S}_{3}$ \\
$\mathbf{6}$ & Ability to obtain and internalize external knowledge resources & $\mathbf{0 . 0 5 5}$ & $\mathrm{r}_{6}=6$ & $\mathrm{E}_{2} \mathrm{~S}_{2}$ \\
$\mathbf{7}$ & Structure of cooperation and knowledge interactions with partners and stakeholders & $\mathbf{0 . 0 2 1}$ & $\mathrm{r}_{7}=7$ & $\mathrm{~S}_{2}$ \\
$\mathbf{8}$ & Structure of turning hidden knowledge to evident and documented resources & $\mathbf{0 . 0 1 9}$ & $\mathrm{r}_{8}=8$ & $\mathrm{P}_{1}$ \\
$\mathbf{9}$ & Integrated knowledge-based relationships with customers and suppliers & $\mathbf{0 . 0 1 7}$ & $\mathrm{r}_{9}=9$ & $\mathrm{~S}_{1}$ \\
$\mathbf{1 0}$ & Requirements and necessities associated with knowledge management environmental & $\mathbf{0 . 0 1 6}$ & $\mathrm{r}_{10}=10$ & $\mathrm{~S}_{3}$ \\
$\mathbf{1 1}$ & Knowledge-supporting codes and regulations & $\mathbf{0 . 0 1 3}$ & $\mathrm{r}_{13}=11$ & $\mathrm{P}_{2}$ \\
$\mathbf{1 2}$ & Official and non-official support for knowledge workers and producers & $\mathbf{0 . 0 1 2}$ & $\mathrm{r}_{12}=12$ & $\mathrm{P}_{3}$ \\
$\mathbf{1 3}$ & Role of knowledge as the basis for evaluating the performance of employees & $\mathbf{0 . 0 1 1}$ & $\mathrm{r}_{14}=13$ & $\mathrm{L \& G}_{1}$ \\
$\mathbf{1 4}$ & Roles and duties formulated for knowledge management & $\mathbf{0 . 0 0 9}$ & $\mathrm{r}_{15}=14$ & $\mathrm{L \& G}_{3}$ \\
$\mathbf{1 5}$ & Updating and learning all knowledge levels & $\mathbf{0 . 0 0 8}$ & $\mathrm{r}_{16}=15$ & $\mathrm{L \& G}_{2}$ \\
$\mathbf{1 6}$ & Ability to cooperate and adapt employees to knowledge changes & $\mathbf{0 . 0 0 5}$ & $\mathrm{r}_{18}=17$ & $\mathrm{SE}_{3}$ \\
$\mathbf{1 7}$ & Knowledge-supporting rules and codes & $\mathbf{0 . 0 0 3}$ & $\mathrm{r}_{7}=18$ & $\mathrm{SE}_{1}$ \\
$\mathbf{1 8}$ & Official and non-official support for knowledge workers and producers & & & $\mathrm{SE}_{2}$ \\
\hline
\end{tabular}

Table 4

Results of prioritization of knowledge management evaluation dimensions with ORESTE

\begin{tabular}{lclc}
\hline Knowledge management evaluation dimensions & Rank & Knowledge management evaluation dimensions & Rank \\
\hline Internal processes & 1 & Stakeholders & 4 \\
Financial & 2 & Staff satisfaction & 5 \\
Growth and learning & 3 & Environment and society & 6 \\
\hline
\end{tabular}

\subsection{Designing BSC for Knowledge Management in Petrochemical Industry}

To prepare a balanced scorecard the quantitative goals of each criterion have to be determined. The goals shall be determined such that they were attainable. Moreover, to attain each quantitative goal and to evaluate the organization special time periods are assigned to the foals. A quantitative goal may reflect the quantitative result of performance assessment at a point in the future (i.e. our desirable performance level in the future). The word "future" is a key to the notion of quantitative goals. When developing quantitative goals it is possible to choose to evaluate the performance against a goal for a specific month, season or year. It is also possible to develop a more long-term goal, which requires a higher level of performance and struggle. One BSC is defined specifically for each dimension. The BSC includes strategies, goals and criteria. Afterwards, in a meeting with the organization's senior managers, quantitative goals are defined for each criterion and planning is carried out for attainment of each foal. The planning involves designation of duties of each workgroup and the time period for each duty. Evaluation of criteria is carried out in the beginning of each plan and at the end of each plan to determine the progress of the job in each item. BSCs are used and support by three groups of users.

1- Viewers: Users who use BSC to supervise and monitor performances.

2- Designers: People who are responsible for creation of score cards.

3- Administrators: People who are responsible for configuring the software and keeping data structures (Rahnamaroodposhti \& Feyzi, 2013).

Tables 5, 6, 7, 8, 9, and 10 present the BSC for the petrochemical industries in each dimension. 
Table 5

BSC for the financial dimension in knowledge management evaluation in petrochemical industries

\begin{tabular}{|c|c|c|c|c|}
\hline Strategy & Goals & Criteria & Quantitative Goals & Schedule \\
\hline \multirow{3}{*}{$\begin{array}{l}\text { Value creation for } \\
\text { stakeholders }\end{array}$} & $\begin{array}{l}\text { Improving personal and } \\
\text { group knowledge }\end{array}$ & Investing in training employees & $5 \%$ increase & Every six months \\
\hline & \multirow{2}{*}{ Profitability } & $\begin{array}{l}\text { Obtaining financial benefits } \\
\text { from institutionalization of } \\
\text { knowledge }\end{array}$ & $5 \%$ increase & $\begin{array}{l}\text { Every three } \\
\text { months }\end{array}$ \\
\hline & & $\begin{array}{l}\text { Attraction of financial resources } \\
\text { and investors to knowledge } \\
\text { processes }\end{array}$ & $6 \%$ increase & Annual \\
\hline
\end{tabular}

\section{Table 6}

BSC for the stakeholders dimension in knowledge management evaluation in petrochemical industries

\begin{tabular}{ccccc}
\hline Strategy & Goals & Criteria & Quantitative Goals & Schedule \\
\hline & $\begin{array}{c}\text { Providing suitable } \\
\text { services }\end{array}$ & $\begin{array}{c}\text { Integrated knowledge-based } \\
\text { relations with customers and } \\
\text { suppliers }\end{array}$ & $5 \%$ increase & $\begin{array}{c}\text { Every three } \\
\text { months }\end{array}$ \\
\cline { 2 - 5 } $\begin{array}{c}\text { Value creation for } \\
\text { customers and } \\
\text { operational } \\
\text { excellence }\end{array}$ & $\begin{array}{c}\text { Requirements and necessities } \\
\text { associated with } \\
\text { of stakeholders }\end{array}$ & $\begin{array}{c}\text { environmental factors of } \\
\text { knowledge management } \\
\text { Structure of cooperation and } \\
\text { knowledge interactions with } \\
\text { partners and stakeholders }\end{array}$ & $8 \%$ increase & $\begin{array}{c}\text { Every three } \\
\text { months }\end{array}$ \\
\hline
\end{tabular}

Table 7

BSC for the internal processes dimension in knowledge management evaluation in petrochemical industries

\begin{tabular}{ccccc}
\hline Strategy & Goals & Criteria & Quantitative goals & Schedule \\
\hline \multirow{2}{*}{$\begin{array}{c}\text { Operational } \\
\text { excellence, growth of } \\
\text { innovation and } \\
\text { creation of } \\
\text { knowledge }\end{array}$} & Aligning the staff & $\begin{array}{c}\text { Knowledge-supporting codes } \\
\text { and regulations }\end{array}$ & $5 \%$ increase & Monthly \\
\cline { 2 - 5 } & $\begin{array}{c}\text { Opfficial and non-official } \\
\text { knowledge workers }\end{array}$ & $\begin{array}{c}\text { support for knowledge } \\
\text { workers and producers } \\
\text { knowledge to evidence and } \\
\text { documented resources }\end{array}$ & $5 \%$ increase & $\begin{array}{c}\text { Every three } \\
\text { months }\end{array}$ \\
\hline
\end{tabular}

Table 8

BSC for the learning and growth dimension in knowledge management evaluation in petrochemical industries

\begin{tabular}{ccccc}
\hline Strategy & Goals & Criteria & Quantitative goals & Schedule \\
\hline $\begin{array}{c}\text { Operational } \\
\text { excellence and } \\
\begin{array}{c}\text { internal value } \\
\text { creation }\end{array}\end{array}$ & Human forces growth & $\begin{array}{c}\text { Role of knowledge as the } \\
\text { basis for evaluating the } \\
\text { performance of employees } \\
\text { Roles and duties formulated } \\
\text { for knowledge management }\end{array}$ & $\begin{array}{c}7 \% \text { increase } \\
\text { Every three } \\
\text { months }\end{array}$ & $\begin{array}{c}\text { Every three } \\
\text { months }\end{array}$ \\
\cline { 2 - 6 } & $\begin{array}{c}\text { Strategy-based } \\
\text { training }\end{array}$ & $\begin{array}{c}\text { Updating and learning all } \\
\text { knowledge levels }\end{array}$ & $10 \%$ increase & $\begin{array}{c}\text { Every three } \\
\text { months }\end{array}$ \\
\hline
\end{tabular}


Table 9

BSC for the staff satisfaction dimension in knowledge management evaluation in petrochemical industries

\begin{tabular}{|c|c|c|c|c|}
\hline Strategy & Goals & Criteria & Quantitative goals & Schedule \\
\hline \multirow{3}{*}{$\begin{array}{l}\text { Operational } \\
\text { excellence }\end{array}$} & \multirow{3}{*}{$\begin{array}{c}\text { Increasing job } \\
\text { satisfaction and } \\
\text { encouraging creation } \\
\text { of new knowledge- } \\
\text { based ideas }\end{array}$} & $\begin{array}{r}\text { Potential for participation and } \\
\text { adapting employees to } \\
\text { knowledge changes }\end{array}$ & $10 \%$ increase & $\begin{array}{l}\text { Every three } \\
\text { months }\end{array}$ \\
\hline & & $\begin{array}{l}\text { Knowledge-supporting } \\
\text { regulations and codes }\end{array}$ & $10 \%$ increase & $\begin{array}{l}\text { Every three } \\
\text { months }\end{array}$ \\
\hline & & $\begin{array}{r}\text { Official and non-official support } \\
\text { for knowledge workers and } \\
\text { producers }\end{array}$ & $10 \%$ increase & $\begin{array}{l}\text { Every three } \\
\text { months }\end{array}$ \\
\hline
\end{tabular}

\section{Table 10}

BSC for the environment and society dimension in knowledge management evaluation in petrochemical industries

\begin{tabular}{|c|c|c|c|c|}
\hline Strategy & Goals & Criteria & Quantitative goals & Schedule \\
\hline \multirow{3}{*}{$\begin{array}{l}\text { Operational } \\
\text { excellence }\end{array}$} & $\begin{array}{l}\text { Participation in oil } \\
\text { projects }\end{array}$ & $\begin{array}{l}\text { Requirements and necessities } \\
\text { associated with environmental } \\
\text { factors }\end{array}$ & $5 \%$ increase & Annual \\
\hline & $\begin{array}{c}\text { Petrochemical } \\
\text { development }\end{array}$ & $\begin{array}{l}\text { External knowledge } \\
\text { resources and their } \\
\text { accessibility }\end{array}$ & $2 \%$ increase & Annual \\
\hline & $\begin{array}{l}\text { Increasing the trust of } \\
\text { foreign investors }\end{array}$ & $\begin{array}{l}\text { Enabling acquisition and } \\
\text { internalization of external } \\
\text { knowledge resources }\end{array}$ & $6 \%$ increase & Every six months \\
\hline
\end{tabular}

\section{Conclusions and Suggestions}

In the present research it was tried to introduce the dimensions and criteria of knowledge management evaluation in petrochemical industries and examine knowledge management performance in Tehran petrochemical industries. It was tried to introduce an executive operational model to take an effective step toward institutionalization and evaluation of knowledge management in this industry. Results of the DEMATEL technique have indicated that the financial dimension maintained the highest effect among the study dimensions. Therefore, decision makers in the field of oil and petrochemical industries are recommended to improve the profitability and increased capital of this industry through financing and attracting foreign investors to petrochemical projects. In addition, the growth and learning dimension received the highest influence as compared to other dimensions, which shows the key role of this dimension in teaching, holding training courses, supporting research projects in the form of knowledge management and related projects, and informing the staff of petrochemical industries.

In this research, after evaluation of knowledge management with ORESTE and identifying the related dimensions and criteria, the internal processes dimension has shown the best performance followed by the financial dimension. Therefore, in view of the results of DEMATEL and actual performance of the Tehran petrochemical industries (with ORESTE) this industry is not in a good place because the financial infrastructure and financial resources have to be available to be able to work on processes, training employees, etc. It is recommended to use the proposed model and BSC (which was proposed in this research) for periodic evaluation of the petrochemical industries.

\section{References}

Feyzi, A., \& Soloukdar, A. (2014). Evaluating performance of the banking industry with FTOPSISBSC approach. Financial Engineering and Securities Management (Portfolio Management), 5(20), 57-78. 
Feyzi, A., Taati, N., \& Hoseinpour, H. (2014). Prioritization of key success factors in implementation and evaluation of knowledge management (passive defense engineering deputy). University of Kashan, National Conference passive defense.

Fontela, E., \& Gabus, A. (1976). Current perceptions of the world problematique. World Modeling: A Dialogue. North-Holland Publishing Company, Amsterdam/Oxford.

Jafari, S.M., Ibn Al-Rasoul, S.A., \& Saee, A. (2009). Knowledge management evaluation with balanced scorecard. Tadbir 205(5).

Kaplan, E. (1983). The assessment of aphasia and related disorders (Vol. 2). Lippincott Williams \& Wilkins.

Khamseh, A., \& Qazayi, H. (2014). Knowledge management evaluation in manufacturing heavy equipment along with improvement solutions (Case Study: HEPCO) (p. 13). Presented in the first international conference on economy, management, accounting, and social sciences, Rasht.

Lin, C. Y., Chen, Y. S., \& Lo, Y. W. (2015). The Impact of Social Capital on the Knowledge Sharing Behavior Among the Community Members of a Social Network Knowledge Platform. In Future Information Technology-II (pp. 183-189). Springer Netherlands.

Luo, S., Du, Y., Liu, P., Xuan, Z. \& Wang, Y. (2015). A study on coevolutionary dynamics of knowledge diffusion and social network structure. Expert Systems With Applications, 42(7), 36193633.

Ngai, E. W. T. \& Chan, E. W. C. (2005). Evaluation of knowledge management tools using AHP. Expert Systems With Applications, 29(4), 889-899.

Oinas-Kukkonen, H. (2006). Toward evaluation of knowledge management with the 7C model. Police Human Development Monthly, 3(8), 22.

Patil, S. K., \& Kant, R. (2014). A fuzzy AHP-TOPSIS framework for ranking the solutions of Knowledge Management adoption in Supply Chain to overcome its barriers. Expert Systems with Applications, 41(2), 679-693.

Rezayinpour, J., Shah Hosseini, M.A., \& Khosravi, S. (2015). A conceptual model based on factors influencing implementation of knowledge management in the System Group Co. Information Development Management Quarterly, 1(4), 79-104

Ribeiro, F. M. (2015). Interdisciplinarity in ferment: the role of knowledge networks and department affiliation. Technological Forecasting and Social Change. http://dx.doi.org/10.1016/i.techfore.2015.07.021

Rahnama Roodposhti, F., Feyzi, A. (2013). Performance evaluation banking industry) using Balanced Scorecard (BSC) - FTOPSIS. MA thesis, Industrial Management, Islamic Azad University Central Tehran Branch.

Serenko, A. \& Dumay, J. (2015). Citation classics published in knowledge management journals. Part I: articles and their characteristics. Journal Of Knowledge Management, 19(2), 401-431.

Sigala, M. \& Chalkiti, K. (2015). Knowledge management, social media and employee creativity. International Journal Of Hospitality Management, 45, 44-58.

Sohrabi, B., Raeesi, I., \& Alidousti, S. (2010). A model for assessing knowledge management maturity in the software industry. Science and Technology Politics, 3(1), 63-79

Samimi, Y. \& Aqayi, A. (2012). A framework for evaluation of knowledge management systems. Industrial Management Quarterly, 10, 24.

Vaezi, R., \& Moslemi, T. (2009). The identification of effective organizational factors influencing the implementation of knowledge management system: The case study of Hamkaran System Company. Journal of Development \& Evolution Management, 1(1), 7-19.

Wiig, K. M. (1997). Knowledge management: where did it come from and where will it go?. Expert systems with applications, 13(1), 1-14.

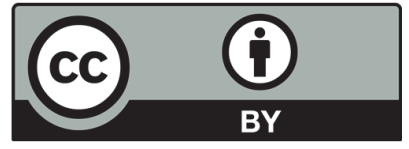

(C) 2016 by the authors; licensee Growing Science, Canada. This is an open access article distributed under the terms and conditions of the Creative Commons Attribution (CC-BY) license (http://creativecommons.org/licenses/by/4.0/). 